\section{Metrics market}

\author{
Measures of research impact are improving, \\ but universities should be wary of their limits.
}

W ith the FIFA World Cup well under way in Brazil (and certain teams already on their way home) there is much analysis of what went wrong for some and what is going right for others. In a parallel effort, marketing departments across the globe are engaged in a final push to link the events on the field with their brands and products.

The result can be a curious, even surreal, blend. Witness the announcement by analytics company Thomson Reuters, for instance, that it was kicking off its own World Cup - of research performance. In the first round, the firm announced that England could have reversed its disappointing loss against Italy had it been playing on the basis of research citation impact. By the same comparison, Australia would have defeated Chile — but the Netherlands would still have crushed Spain. Four more rounds of elimination will pit countries against each other in terms of their proportion of international collaborations, highly cited papers and relative world impact. Who can wait for the United States-Switzerland semi-final?

This gimmicky tie-in illustrates a trend that deserves attention: the retooling of the bibliometrics industry. Thomson Reuters was promoting the updated range of bibliometric indicators in its research analytics service, InCites. And it is not the only company to have refreshed its bibliometrics offerings for 2014.

Since January, Elsevier has been promoting the next generation of its SciVal product, and on 12 June, Altmetric (supported by Macmillan Science and Education, which owns Nature Publishing Group, the publishers of Nature) launched its own commercial offering for research institutions: a tool to track the online impact of faculty members' academic papers. One intriguing metric that was launched in April for the Lens database, run by the non-profit organization Cambia in Canberra, allows researchers to freely examine how many patents have cited their papers, although currently only the life sciences are included.
Products offered by commercial analytics firms are worth watching because they generally determine how research institutions track and assess their scholars. The latest products mean that it is now easier than ever to calculate a dizzying range of metrics for any group of papers including aggregations of papers at the level of the individual or the faculty, as well as the country.

On the plus side, this new generation of products is more sophisticated and takes into account the insights and criticisms of bibliometrics experts. The tools now tend to focus on individual research papers as a core unit of output, rather than the journal in which a paper is published. And they increasingly recognize that it is only meaningful to compare metrics in context: for instance, normalizing for performance relative to papers of a similar age, research field

"It is easier than
ever to calculate
a dizzying range
of metrics for
any group of
papers."
and publication venue.

But on the minus side, it is still easy to misuse these offerings. The latest breed of bibliometrics is useful as a marketing tool for individuals, as a way to spot unnoticed pockets of excellence and, yes, even to rank countries or institutions in a research World Cup. But there is a risk that universities are buying increasingly sophisticated products to track their performance without really understanding the limitations of such metrics. On page 470, Jonathan Adams reviews Beyond Bibliometrics, a book that outlines the history and future direction of attempts to measure scholarly impact. The editors, Blaise Cronin and Cassidy Sugimoto, urge caution. Adams asks: "Even after decades of use, do we really understand what citation data are and what we do with them? Do those who use bibliometrics have clear criteria for how they employ and interpret them?"

As this journal has noted before (see www.nature.com/metrics), many researchers feel under stress from their attempts to maximize the metrics by which their academic success is judged. It has never been more important to demand clarity and transparency from research managers on exactly which metrics they are using to evaluate scholars, and why. With this next generation of commercial tools, it does not seem so fanciful to picture a senior manager somewhere in your research institution engaged in a kind of perpetual departmental World Cup, scrolling through screeds of bar charts and playing 'fantasy faculty' with the careers of researchers.

\section{Storm warning}

Environmentalists are divided over whether it is possible to have a 'good' Anthropocene.

W inston Churchill called it the enemy within. Leonardo da Vinci noted that: "As every divided kingdom falls, so every mind divided between many studies confounds and saps itself." If there is one word that sums up current attitudes to the climate problem and society's response to it, then it is 'divided'. And that describes just the attitudes of those who agree that there is a serious problem to deal with.

Those who do not accept this reality - for whatever reasons - must have been rubbing their hands this week as arguments raged among their opponents. There is a new term in town - 'ecopragmatist'. It can be used both as a compliment and an insult.

The lightning rod for the latest storm was a fairly benign talk given in New York this month by New York Times environment writer Andrew Revkin on the difficulty of applying numerical targets and goals, on carbon emissions say, to real-world behaviour. It might have gone largely unnoticed, except that Revkin included in the talk's title the idea of a 'good' Anthropocene - the informal name for the period, beginning

at the Industrial Revolution, in which humans have substantially altered Earth's ecosystems. To place the words 'good' and 'Anthropocene' together, even with the former in quotation marks, is heresy to some. In Scientific American on 19 June, the Australian ethicist Clive Hamilton delivered a broadside against those who argue that human ingenuity, not behaviour change, is the best response to rising carbon emissions. "Such unbounded optimism is dangerous, wishful thinking," he wrote, because it plays into the hands of those who would protect the status quo, whatever the environmental consequences.

Perhaps there is more to this than division along the optimismpessimism axis; whether someone is the sort of person who sees an atmosphere half-full or half-empty of carbon dioxide. As is made clear in a useful report published this week by the UCL Policy Commission on Communicating Climate Science in London, public discussion of climate change has deeper psychological roots. It is "as much about what sort of world we wish to live in, and hence about ethics and values, as it is about material risks to human wellbeing".

The report is, for want of a better word, ecopragmatic. It acknowledges an awkward truth: if climate scientists are failing to get their message across to the wider public, then it could be the message that is the

$\rightarrow$ NATURE.COM To comment online, click on Editorials at: go.nature.com/xhunqv problem, not the public. The authors of the report acknowledge that some of their conclusions are controversial - scientists must learn to tell stories rather than report cold facts, for instance - but they deserve discussion. 